\title{
Hepatitis B Sero-Prevalence and Risk Behaviors Among Immigrant Men in a Population-Based Household Survey in Low-Income Neighborhoods of Northern California
}

\author{
Vivian Levy $\cdot$ Jinwei Yuan · Juan Ruiz · Scott Morrow $\cdot$ Juan Reardon • \\ Mathew Facer · Fred Molitor • Barbara Allen • Barbara Green Ajufo • \\ Geneva Bell-Sanford · Willi McFarland · Henry F. Raymond • \\ Tim Kellogg $\cdot$ Kimberly Page
}

Published online: 25 March 2009

(c) The Author(s) 2009. This article is published with open access at Springerlink.com

\begin{abstract}
Background Despite an effective vaccine, 60,000 new HBV infections were reported in the US in 2004; $95 \%$ in adults. We evaluate HBV sero-prevalence, risk behaviors and self-reported vaccination among Latino immigrant, Asian immigrant and US born low income men in five northern California counties. Methods Population based, cross sectional survey of $\mathrm{HBV}$
\end{abstract}

V. Levy $(\bowtie) \cdot$ S. Morrow

San Mateo County Health Department, San Mateo Medical Center- Edison Clinic, 222 W. 39th Avenue, San Mateo,

CA 94403, USA

e-mail: vlevy@stanford.edu

J. Yuan

University of California Los Angeles, Los Angeles, CA, USA

J. Ruiz · M. Facer · F. Molitor

California Department of Health Services, Office of AIDS,

Sacramento, CA, USA

J. Reardon

Contra Costa County Department of Public Health, Martinez,

CA, USA

B. Allen · B. G. Ajufo

Alameda County Public Health, Oakland, CA, USA

G. Bell-Sanford

San Joaquin County Public Health Services, Stockton, CA, USA

W. McFarland · H. F. Raymond · T. Kellogg

San Francisco Department of Public Health, HIV/AIDS Statistics

and Epidemiology Unit, San Francisco, CA, USA

K. Page

Department of Epidemiology and Biostatistics, University

of California San Francisco, San Francisco, CA, USA sero-prevalence and risk behaviors in men aged 18 to 35 years. Results Among 1,512 men screened, Asian immigrants were most likely to have had prior HBV infection (15.1\%) and chronic infection (3.8\%) compared to US born (prior 5.1\%, chronic $0.6 \%$ ) and Latino immigrant men (prior 2.0\%, chronic 0.3\%.) Reported HBV vaccination was lowest for Latino immigrants (12\%) compared to Asian immigrants and US born men (35\% in both.) Latino immigrants reported less educational attainment, medical insurance coverage and access to a physician in the last six months. Discussion Healthcare providers should routinely screen Asian immigrants for $\mathrm{HBV}$ regardless of their self reported vaccination status. Latino immigrants may comprise an important group of under-vaccinated, at risk persons in California. HBV testing and vaccination of immigrants soon after US arrival should be encouraged.

Keywords Hepatitis B - Hepatitis B vaccine . Immigrants $\cdot$ California

\section{Background}

Hepatitis $\mathrm{B}$, a vaccine preventable viral infection, infects more than 350 million persons globally and accounts for more than one million deaths annually from cirrhosis or hepatocellular carcinoma [1]. In high prevalence areas, such as China and Southeast Asia, the majority of infections are vertically acquired in the neonatal period or horizontally acquired as children [2]. In low prevalence areas, such as the United States and Mexico, hepatitis B virus (HBV) is mainly a sexually transmitted infection (STI) [3-5]. The US strategy to eliminate HBV consists of identification of chronically infected persons who serve as 
reservoirs of infection and vaccination of susceptible persons with a safe, effective HBV vaccine. Early identification of persons with chronic HBV infection interrupts ongoing transmission by promoting the identification and vaccination of susceptible household contacts and sex partners. All persons with chronic HBV infection should be referred for medical management to be evaluated for antiviral therapy and other treatments and to be monitored for cirrhosis and liver cancer.

HBV incidence remains highest in adults, who accounted for $95 \%$ of the estimated 60,000 new infections in 2004 [6]. Since 1999, the incidence of acute hepatitis B increased 5\% among males aged 20-39 years and 20\% and $31 \%$, respectively, among males and females aged $>40$ years. Acute hepatitis B incidence has been consistently higher among men than women, with a male-to female ratio of 1.5 in 1990 and 1.7 in 2002. [7].

\section{Conceptual Framework}

In addition to the behavioral risk groups of men who have sex with men (MSM) and injection drug users, the CDC now recommends routine hepatitis B surface antigen (HBsAg) testing for persons born in geographic regions where $\mathrm{HBsAg}$ prevalence is greater than or equal to $2 \%$ [8.] California, with a population that is $26 \%$ foreign-born [9] is the largest immigrant receiving state in the US. Globally, HBsAg prevalence is high $(>8 \%)$ or intermediate $(2-7 \%)$ in all countries of Asia (Southeast Asia, East Asia and Northern Asia) and in all countries of the South Pacific except Australia and New Zealand. For Mexico and Central America, the main source of Latin American immigrants to California, only Guatemala and Honduras have HBsAg prevalence $\geq 2 \%$ [8]. Immigrant Asian/Pacific Islanders (A/PI) in the US and US born persons not vaccinated as infants whose parents were born in Asia/Pacific Islands are a well recognized target group for HBV screening and vaccination efforts. Others have reported chronic HBV infection prevalence of $8.9 \%$ among Asian-American adult volunteers in the San Francisco Bay area [10], 7\% among 2,545 refugees to Minnesota [11], and $14 \%$ among Vietnamese immigrants to Boston [12]. Latin American immigrants to California, many of who first arrive to the US as labor migrants in adolescence and young adulthood, may be at higher risk for HBV infection because of undervaccination, and sexual risk exposures. In this population based study, we evaluate HBV sero-prevalence, risk behaviors and self-reported vaccination completion among low-income immigrant men compared to lowincome US born men in five northern California counties.

\section{Methods}

Participants

Participants were recruited for the HEY Man (Health Evaluation in Young Men) Study, a population-based, cross sectional survey of HIV infection, STIs including $\mathrm{HBV}$, and associated risk behaviors in men aged 18 to 35 years residing in low income neighborhoods in five northern California counties.

\section{Data Collection}

The study design followed a protocol similar to the Northern California Young Women's Survey. [13] In brief, men, age $18-35$ years, were recruited within a lowincome target area defined as U.S. Census block groups with median household income below the 10th percentile for five San Francisco Bay Area counties: Alameda, Contra Costa, San Francisco, San Joaquin and San Mateo. Because the 2000 U.S. Census data were not available at the time of planning the survey, median household income levels were obtained for the year 2002 using commercially available estimates (Claritas, San Diego, CA). Block group boundaries used the 1990 U.S. Census. We later verified that the target areas were not substantially changed after the 2000 U.S. Census data were made available. First, we examined how much the overall boundaries of the target area changed from 1990 to 2000. These boundaries made only minor changes to the total target area and did not include or omit any new neighborhoods. Second, we examined how many actually sampled city blocks fell outside the 2,000 target boundaries and found that none did. Within the target area, a simple random sample of city blocks was selected.

Field staff contacted all households within the sampled city blocks to identify eligible male residents. Residents were eligible if they spent the previous night in the household and had no other residence, and were 18 to 35 years of age. Of 17,295 households identified, $85.8 \%$ were successfully contacted (range $76.8 \%$ in Alameda to $96.6 \%$ in San Joaquin). Of 2,937 eligible men identified, $60.6 \%$ agreed to enroll in the study (range $53.3 \%$ in Alameda to $69.2 \%$ in Contra Costa).

\section{Measures}

Field staff administered structured interviews in Spanish or English based on the subject's preference. Interviewers assessed demographic characteristics, sexual risk behaviors, substance use and access to medical care including prior HBV vaccinations. All men provided urine to test for gonococcal and chlamydial infection using nucleic acid 
amplification testing and serum for HBV core antibody (anti-HBc), syphilis testing using RPR and HIV ELISA. All serum specimens found to be positive for anti-HBc, were tested for HBsAg. Participants were considered to have past $\mathrm{HBV}$ infection if they tested positive with an isolated anti-HBc and to have chronic $\mathrm{HBV}$ infection if they tested positive for both anti-HBc and HBsAg.

Latino immigrants were defined as men who were born outside the U.S. and identified their ethnicity as "Latino or Hispanic." Asian immigrants were defined as men who were born outside the U.S. and identified their ethnicity as "Asian or Pacific Islanders." In the current report, we compare $\mathrm{HBV}$ risk related behaviors and $\mathrm{HBV}$ prevalence among Latino immigrant, Asian immigrant and US-born low-income men.

\section{Analysis}

Point prevalence estimates and $95 \%$ confidence intervals (CIs) were calculated to account for the 1-stage, cluster sample design. Probability weights were constructed using the relative probability of being included in the sample and were based on the sizes of the target populations by county (males aged 18-34 years with household median income below the 10th percentile) as estimated in the 1990 census.
Statistical tests (Chi-square, Fisher's exact) for comparisons among the three groups used two-sided $P$ values. Because crude prevalence estimates in the sample differed from the survey-adjusted estimates, we present only weighted percentages. Multiple logistic regression was used to assess independent associations between prior $\mathrm{HBV}$ infection and predictor variables including demographic, access to medical care, and risk exposures and prior HBV infection using forward and backward stepwise selection methods. All analyses were conducted using SAS version 8.0 (SAS Institute, Cary, NC).

The study protocol was approved by the human subjects committees of the University of California San Francisco and the State of California Health and Welfare Agency. All interviewed men provided signed informed consent.

\section{Results}

Weight-adjusted demographics, access to medical care including any hepatitis $\mathrm{B}$ vaccination, and $\mathrm{HBV}$ risk behaviors are summarized in Table 1. Latino immigrants comprised $42 \%$ (631 of 1,502) of men enrolled in the main HEYMan study. Among Latino immigrants, the vast majority was from Mexico (81.6\%). Latino immigrants

Table 1 Weight-adjusted demographic characteristics, HBV risk-related behavior and vaccination history among Asian immigrants, Latino immigrants and US-Born Men in a population-based household survey of low-income areas of Northern California, 2001-2004 $(n=1,502)^{\mathrm{a}, \mathrm{b}}$

\begin{tabular}{|c|c|c|c|c|c|c|c|c|c|}
\hline \multirow[t]{3}{*}{ Variable } & \multirow{2}{*}{\multicolumn{2}{|c|}{$\begin{array}{l}\text { Total } \\
n=1,502\end{array}$}} & \multirow{2}{*}{\multicolumn{2}{|c|}{$\begin{array}{l}\text { Asian immigrants } \\
n=53\end{array}$}} & \multirow{2}{*}{\multicolumn{2}{|c|}{$\frac{\text { Latin American immigrants }}{n=631}$}} & \multirow{2}{*}{\multicolumn{2}{|c|}{$\begin{array}{l}\text { US born } \\
n=818\end{array}$}} & \multirow{3}{*}{$\begin{array}{l}P \text { Value } \\
\text { IQR }\end{array}$} \\
\hline & & & & & & & & & \\
\hline & & Median & IQR & Median & IQR & Median & IQR & Median & \\
\hline Age & 24 & $21-29$ & 23 & $20-28$ & 25 & $22-30$ & 24 & $20-29$ & \\
\hline Median monthly income & 1,000 & $480-1,600$ & 1,050 & $400-2,000$ & 1,200 & $800-1,600$ & 800 & $300-1,600$ & \\
\hline & & $\%$ & & $\%$ & & $\%$ & & $\%$ & \\
\hline$<$ High school education & & 36.4 & & 7.9 & & 53.2 & & .3 & $<0.01$ \\
\hline Any medical insurance & & 42.4 & & 63.5 & & 26.1 & & 3.6 & $<0.01$ \\
\hline Seen doctor in last 6 months & & 36.9 & & 36.0 & & 24.0 & & 7.0 & $<0.01$ \\
\hline Any sex partner in last $6 \mathrm{mos}$ & & 75.8 & & 66.0 & & 70.8 & & .2 & $<0.01$ \\
\hline $\begin{array}{l}\text { Multiple sex partners } \\
\text { in past } 6 \text { mos }\end{array}$ & & 30.3 & & 31.0 & & 23.5 & & 5.5 & $<0.01$ \\
\hline Ever paid someone for sex & & 19.8 & & 11.6 & & 35.8 & & 9 & $<0.01$ \\
\hline Ever been paid for sex & & 4.7 & & 5.8 & & 1.5 & & 1 & $<0.01$ \\
\hline Transfusion history & & 3.9 & & 5.4 & & 2.9 & & 6 & 0.19 \\
\hline Gonorrhea prior diagnosis & & 4.3 & & 2.0 & & 2.1 & & 2 & $<0.01$ \\
\hline Chlamydia prior diagnosis & & 4.4 & & 4.0 & & 2.3 & & 0 & $<0.01$ \\
\hline Injection drug use history & & 3.4 & & 1.4 & & 0.8 & & .5 & $<0.01$ \\
\hline HBV Vaccination reported & & 25.2 & & 34.9 & & 11.8 & & 5.0 & $<0.01$ \\
\hline
\end{tabular}

a Ten men did not have complete interview data

${ }^{\mathrm{b}}$ Because crude prevalence estimates in the sample differed from the survey-adjusted estimates, we present only weighted percentages 
were less likely to have a high school education, $(P<0.01)$ to have any medical insurance, $(P<0.01)$ to have visited a physician in the last six months $(P<0.01)$ and to report any prior vaccination for hepatitis $\mathrm{B}$ $(P<0.01)$ compared to Asian immigrants or US born men. Only $11.8 \%$ of Latino immigrants reported any prior hepatitis $\mathrm{B}$ vaccination compared to $35 \%$ among Asian immigrants and US born men. $(P<0.01)$.

The majority of immigrant men were sexually active within the last six months (66\% for Asian and $70.8 \%$ for Latino immigrants respectively.) Latino immigrants (35.8\%) compared with Asian immigrants (11.6\%) and US born men (7.9\%) were more likely to report having had sex with a commercial sex worker. Among men who reported a sex partner in the last six months (75.4\%), approximately $60 \%$ replied that they used male condoms to avoid STIs, with no significant difference among Latino immigrants, Asian immigrants or US born men. Transfusion history was highest among Asian immigrants (5.4\%) compared to Latino immigrants $(2.9 \%)$ or US born $(4.6 \%, P=0.19$.) US born men more often reported prior injection drug use (5.5\%) compared to Asian (1.4\%) or Latino (0.8\%) immigrants.

Prior HBV exposure was most common among Asian immigrants (15.1\%) compared to Latino immigrants (2.0\%) and U.S. born men (5.1\%) (Table 2). Chronic HBV infection was also most prevalent among Asian immigrants (3.8\%) compared to less than $1 \%$ in Latino immigrants and U.S. born men (Table 2). Among immigrants with past HBV infection, Asian immigrants were younger at first U.S. arrival (median age 14 years, interquartile range 8-14 years) than Latino immigrants (median age 17 years, interquartile range 15-21 years). In the final multiple logistic regression model (Table 3), variables which remained significantly associated with prior HBV infection were Asian or Latino immigrant status, ever being paid for sex, and any injection drug use.

\section{Discussion}

In this population based sample of low income men, Asian immigrants were four times as likely as U.S. born men to have had past HBV infection. This is consistent with
Table 3 Logistic regression analysis of factors associated with prior HBV infection among Asian immigrants, Latin American immigrants and US-Born men in a population based household survey of low income areas of Northern California $(n=1512)$

\begin{tabular}{llcr}
\hline Variable & $\begin{array}{l}\text { Odds ratio (95\% Confidence } \\
\text { Interval) }\end{array}$ & $P$ value \\
\hline Immigrant category & & & \\
US born & 1.0 & $(1.78-9.1)$ & $<0.01$ \\
Asian immigrants & 4.0 & $(0.24-0.89)$ & 0.02 \\
Latino immigrants & 0.46 & & \\
Ever been paid for sex & & \\
No & 1.0 & $(1.0-5.2)$ & $<0.05$ \\
Yes & 2.3 & & \\
Injection drug use history & & \\
No & 1.0 & $(1.8-9.1)$ & $<0.01$ \\
Yes & 4.0 &
\end{tabular}

previous reports documenting significantly increased prevalence of HBV infection in US A/PI populations [8, 14].

The prevalence of chronic and past HBV infection we report in Latino immigrants ( $0.3 \%$ and $2.0 \%$ respectively) is slightly higher than that reported from general population surveys in Mexico (0.1\% chronic HBV infection and $1.4 \%$ past HBV infection) [4]. This modest difference in HBV sero-prevalence may reflect sexually acquired disease and under-vaccination in Latino immigrants. This group had the highest proportion (35.8\%) reporting a history of sex with a commercial sex worker (CSW), a finding consistent with other studies of Latino immigrants. [15, 16] Sexual exposure remains the main route for HBV infection among U.S. adults [17], and injection drug use is also a significant risk. [18] Consistent with that, a significantly higher proportion of U.S. born men compared to immigrant men reported multiple sex partners and IDU exposure.

We found Latin American immigrants compared to other low income men were less likely to report any prior HBV vaccination (11.8\% vs. $35 \%$.) This finding is consistent with a recent national interview survey that found self report of hepatitis B vaccination was associated with certain population characteristics including female sex, non-Hispanic ethnicity, higher education and health insurance [6].

Table 2 Chronic and prior HBV infection and HCV infection among Asian immigrants, Latin American immigrants and U.S-Born men in a population based household survey of low income areas of Northern California, 2001-2005 $(n=1512)$

\begin{tabular}{|c|c|c|c|c|c|}
\hline Variable & $\begin{array}{l}\text { Total } \\
n=1512\end{array}$ & $\begin{array}{l}\text { Asian immigrants } \\
n=53\end{array}$ & $\begin{array}{l}\text { Latin American immigrant } \\
n=648\end{array}$ & $\begin{array}{l}\text { US born } \\
n=811\end{array}$ & $P$ Value* \\
\hline Chronic HBV infection (HBsAg+, anti-HBc+) & $9(0.60 \%)$ & $2(3.77 \%)$ & $2(0.31 \%)$ & $5(0.62 \%)$ & 0.03 \\
\hline Prior HBV infection (isolated anti-HBc+) & $62(4.10 \%)$ & $8(15.09 \%)$ & $13(2.01 \%)$ & $41(5.06 \%)$ & $<0.01$ \\
\hline HCV infection (by RIBA) & $20(1.32 \%)$ & $0(0 \%)$ & $3(0.46 \%)$ & $17(2.10 \%)$ & 0.02 \\
\hline
\end{tabular}

* Fisher exact test 
Several limitations of this study exist. Interviews were available only in English and Spanish, thereby limiting participation by other recent immigrants such as Cantonese speakers and other Asians. While Asian immigrants comprise a small number of study participants, the strength of findings in this population based study with regard to Asian immigrants sampled are statistically and clinically significant. This population based study sampled housed, low income men thereby omitting high risk men who were unstably housed, homeless, in drug treatment programs, or in the correctional system. It is also possible that selection bias could have resulted in underestimates of HBV exposure if non-response rates were associated with HBV infection. Demographic differences between study responders and non-responders were not evaluated. We were unable to assess if there were differential exposures in the two groups. Perhaps most importantly, serologic testing for hepatitis B surface antibody (anti-HBs), the marker of immunity from vaccination, was not measured in participants and therefore self-reported vaccination history could not be corroborated. In a non-random study of six Bay area cities where Asians constituted over $30 \%$ of the population in each city, $12 \%$ (381 of 3,163) of participants reported having been vaccinated against HBV. Of these persons, 20\% lacked protective antibodies and 5\% were found to be chronically HBV infected [10]. This documents the discrepancy between reported vaccine status and anti-HBs seroprevalence.

\section{New Contribution to the Literature}

Well publicized and funded campaigns for screening and vaccinating $\mathrm{A} / \mathrm{PI}$ immigrants for $\mathrm{HBV}$ in Northern California are critical. Our findings suggest Latin American immigrants in California comprise pockets of need with substantial numbers of under-vaccinated persons. Recommendations call for immigrants to undergo a health assessment soon after arrival in the US to evaluate for common infectious diseases, update immunizations and provide primary care services. [19, 20] Medical screening of immigrants from countries of intermediate and high HBV endemicity into the US soon after their arrival represents an opportunity for HBsAg and anti-HBs testing. The hepatitis B vaccination series should be started even when completion cannot be guaranteed since protective levels of antibody develop after a single dose of hepatitis B vaccine in $30-50 \%$ of healthy young adults, and after two doses in $75 \%$ of healthy young adults [21].

As sexual exposure remains a primary route for $\mathrm{HBV}$ infection, wider availability of HBV vaccine in sexually transmitted disease clinics is important; currently less than $25 \%$ of sexually transmitted disease clinics provide hepatitis B vaccination [22]. As well, collaborative efforts by local, state, federal, and private stakeholders will be needed to implement $\mathrm{HBV}$ testing and vaccination recommendations in primary care settings, mobile van and adult immunization clinics, STD clinics, correctional facilities and drug treatment centers. California is an important testing ground for these efforts at integration [11, 22].

Acknowledgments This study was funded by the California Department of Health Services (Grant number 03-75821). Dr. Page also received salary support from NIH 2 R01 DA016017-03A1.

Open Access This article is distributed under the terms of the Creative Commons Attribution Noncommercial License which permits any noncommercial use, distribution, and reproduction in any medium, provided the original author(s) and source are credited.

\section{References}

1. Lee WM. Hepatitis B virus infection. The New England Journal of Medicine. 1997;337:1733-45. doi:10.1056/NEJM19971211337 2406.

2. Kane M. Global programme for control of hepatitis B infection. Vaccine. 1995;13:S47-9.

3. Advisory Committee on Immunization Practices. A comprehensive immunization strategy to eliminate transmission of Hepatitis B virus in the United States Part II: immunization of adults. MMWR Morbidity and Mortality Weekly Report. 2006;55(RR-16): $1-26$.

4. Silveira TR, Fonseca JCD, Rivera L, et al. Hepatitis B seroprevalence in Latin America. Pan American Journal of Public Health. 1999;6(6):378-83.

5. Fay OH. Hepatitis B in Latin America: epidemiological patterns and eradication strategy. The Latin American Regional Study Group. Vaccine 1990;8 Suppl:S100-6. doi:10.1016/0264-410X (90)90228-E.

6. Centers for Disease Control and Prevention. Hepatitis B vaccination coverage among adults-United States, 2004. MMWR Morbidity and Mortality Weekly Report. 2006;55(18):509-11.

7. Centers for Disease Control, Prevention. Incidence of acute hepatitis B- United States, 1990-2002. MMWR. 2004;52:1252-4.

8. Centers for Disease Control and Prevention. Recommendations for identification and public health management of persons with chronic hepatitis B infection. MMWR Morbidity and Mortality Weekly Report. 2008;57(RR-8):1-20.

9. 2000 U.S. Census, Tables P1, P21, PCT19. At: www.census.gov.

10. Lin SY, Chang ET, So SK. Why we should routinely screen Asian American adults for hepatitis B: a cross sectional study of Asians in California. Hepatology (Baltimore, Md.). 2007;46(4): 1034-40. doi:10.1002/hep.21784.

11. Lifson AR, Thai D, O'Fallon A, Mills WA, Hang K. Prevalence of tuberculosis, hepatitis B virus, and intestinal parasitic infections among refugees to Minnesota. Public Health Reports. 2002; 117:69-77.

12. Nelson K, Bui H, Samet JH. Screening in special populations: a "case study" of recent Vietnamese immigrants. The American Journal of Medicine. 1997;102:435-40. doi:10.1016/S00029343(97)89443-0.

13. Ruiz JD, Molitor F, McFarland W, et al. Prevalence of HIV infection, sexually transmitted diseases, and hepatitis and related risk behavior in young women living in low-income neighborhoods of northern California. The Western Journal of Medicine. 2000;172:368-73. doi:10.1136/ewjm.172.6.368. 
14. Centers for Disease Control and Prevention. Screening for chronic hepatitis B among Asian/Pacific Islander populationsNew York City, 2005. MMWR Morbidity and Mortality Weekly Report. 2006;55:505-9.

15. Lopez R, \& Ruiz JD Seroprevalence of Human immunodeficiency virus type 1 and syphilis and assessment of risk factors among migrant and seasonal farmworkers in Northern California. Sacramento: Office of AIDS, California Department of Health Services; 1995.

16. Organista KC, Balls-Organista PB, Garcia de Alba JE, Castillo Moran MA, Ureta Carrillo LE. Survey of condom related beliefs, behaviors, and perceived social norms in Mexican migrant laborers. Journal of Community Health. 1997;22:185-98. doi: 10.1023/A:1025173008088.

17. Goldstein ST, Alter MJ, Williams IT, et al. Incidence and risk factors for acute hepatitis B in the United States, 1982-1998: implications for vaccination programs. The Journal of Infectious Diseases. 2002;185:713-9. doi:10.1086/339192.

18. Hagan H, McGough JP, Thiede H, Weiss NS, Hopkins S, Alexander ER. Syringe exhange and risk of infection with hepatitis B and C viruses. American Journal of Epidemiology. 1999;149:203-13.
19. Walker PF, Jaranson J. Refugee and immigrant health care. The Medical Clinics of North America. 1999;83:1104-21.

20. Barnett ED. Infectious disease screening for refugees resettled in the United States. Clinical Infectious Diseases. 2004;39:833-41. doi:10.1086/423179.

21. Weinbaum C, Lyerla R, \& Margolis HS. Prevention and control of infections with hepatitis virus in correctional settings. MMWR Morbidity and Mortality Weekly Report. 2003;52(RR-1):1-36.

22. Wilson BC, Moyer L, Schmid G, et al. Hepatitis B vaccination in sexually transmitted disease (STD) clinics: a survey of STD programs. Sexually Transmitted Diseases. 2001;28(3):148-52. doi:10.1097/00007435-200103000-00005. 